\title{
Biocarvão de caroço de açaí no desenvolvimento de mudas de paricá [Schizolobium parahyba var. amazonicum (Huber ex Ducke) Barneby]
}

\begin{abstract}
No município de Belém há elevada produção de resíduos advindos do beneficiamento do caroço de açaí, em virtude deste fruto ser um produto que mobiliza o setor econômico da capital. Sabe-se que este resíduo pode servir como matéria-prima para a confecção de filtros no tratamento de água, na fabricação de alimentos à animais, na composição de artesanatos, além de servir como componente na preparação de substratos para desenvolvimento de plantas. Objetivou-se com este trabalho avaliar semanalmente o desenvolvimento de mudas de Paricá (Shizolobium amazonicum) em Latossolo Amarelo de textura média misturado em diferentes proporções com Biocarvão de Caroço de Açaí (BCA) por 40 dias. Os experimentos foram dispostos em casa de vegetação com delineamento inteiramente casualizado, totalizando dez tratamentos e quatro repetições. As variáveis analisadas foram altura da parte aérea (APA), diâmetro do coleto (DC), matéria seca da parte aérea (MSPA) e matéria seca de raiz (MSR). Os tratamentos constaram de diferentes proporções de solo e BCA ( $\left.350^{\circ} \mathrm{C}\right)$. Os dados foram tratados e submetidos à análise de variância (ANOVA) $(p<0,05)$ e comparados pelo teste $t$, por meio do software ASSISTAT Versão 7.7. Após 7 dias do transplantio das mudas, todos os tratamentos que continham biocarvão $\left(350^{\circ} \mathrm{C}\right)$ tiveram suas bases do coletos queimadas e não se desenvolveram. 0 tratamento $\mathrm{T} 3(100 \%$ solo com calagem, sem adubação) proporcionou melhor desenvolvimento das mudas de Paricá, com maior crescimento em altura $(23,37 \mathrm{~cm})$, diâmetro do coleto $(3,89 \mathrm{~mm})$, MSPA $(1,68 \mathrm{~g})$, MSR $(0,67 \mathrm{~g})$, MST $(2,36 \mathrm{~g})$, assim como um índice de qualidade de Dickson $(0,27)$ considerado adequado. Logo, verificou-se que o BCA não propiciou bom desenvolvimento nas espécies quando misturado ao solo.
\end{abstract}

\section{Biochar of açaí stone in the development of paricá seedlings [Schizolobium parahyba var. amazonicum (Huber ex Ducke) Barneby]}

\begin{abstract}
In the municipality of Belém, there is a high production of residues resulting from the processing of the açai stone, as this fruit is a product that mobilizes the capital's economic sector. It is known that this residue can serve as a raw material for making filters in water treatment, in the manufacture of animal feed, in the composition of handicrafts, in addition to serving as a component in the preparation of substrates for plant development. The objective of this work was to evaluate the development of Paricá seedlings (Shizolobium amazonicum) in medium-textured Yellow Latosol mixed in different proportions with Caroço de Açaí Biochar (BCA) for 40 days weekly. The experiments were arranged in a greenhouse with a completely randomized design, totaling ten treatments and four replications. The variables analyzed were shoot height (APA), stem diameter (DC), shoot dry matter (MSPA) and root dry matter (MSR). The treatments consisted of different proportions of soil and BCA $\left(350^{\circ} \mathrm{C}\right)$. The data were treated and submitted to analysis of variance (ANOVA) $(\mathrm{p}<0.05)$ and compared using the $t$ test, using the ASSISTAT Version 7.7 software. After 7 days of transplanting the seedlings, all treatments that contained biochar $\left(350^{\circ} \mathrm{C}\right)$ had their collecting bases burned and did not develop. the T3 treatment (100\% soil with liming, without fertilization) provided better development of the Paricá seedlings, with greater growth in height $(23,37 \mathrm{~cm})$, diameter of the collection $(3.89 \mathrm{~mm}), \mathrm{MSPA}(1.68 \mathrm{~g}), \mathrm{MSR}(0.67 \mathrm{~g}), \mathrm{MST}(2.36 \mathrm{~g})$, as well as a Dickson quality index $(0.27)$ considered adequate. Therefore, it was found that BCA did not provide good development in species when mixed with soil.
\end{abstract}

Keywords: Biochar; Açaí; Paricá; Organic waste; Recovery of Degraded Areas.

Topic: Uso de Recursos Naturais

Reviewed anonymously in the process of blind peer.

Leandro Marques Torres (iD

Universidade Federal Rural da Amazônia, Brasil

http://lattes.cnpq.br/2678860527695504

http://orcid.org/0000-0001-5976-6340

leandrotorres15@yahoo.com.br

Lorena Fernanda Araújo Soares (iD)

Universidade Federal do Pará, Brasil

http://lattes.cnpq.br/3424684009064743

http://orcid.org/0000-0002-3757-2155

lorenaasoaares@gmail.com

\section{Sarah Dias Azevedo}

Universidade Federal Rural da Amazônia, Brasil

http://lattes.cnpq.br/7721203184014688

http://orcid.org/0000-0002-5105-1794

saaahazevedo@gmail.com

d

DOI: 10.6008/CBPC2179-6858.2021.001.0049
Received: 03/01/2021

Approved: 28/01/2021

Suzana Romeiro Araújo (ib)

Universidade Federal Rural da Amazônia, Brasil

http://lattes.cnpq.br/7289473902924417

http://orcid.org/0000-0002-3569-8440

suzanaromeiro@yahoo.com.br

Regilene Angélica da Silva Souza

Universidade Federal Rural da Amazônia, Brasil

http://lattes.cnpq.br/0574812911676652

regilenesouza@yahoo.com.br

Referencing this:

TORRES, L. M.; SOARES, L. F. A.; AZEVEDO, S. D.; ARAÚJO, S. R.; SOUZA, R. A. S.. Biocarvão de caroço de açaí no desenvolvimento de mudas de paricá [Schizolobium parahyba var. amazonicum (Huber ex Ducke) Barneby]. Revista Ibero Americana de Ciências Ambientais, v.12, n.1, p.615-624, 2021. DOI: http://doi.org/10.6008/CBPC2179

6858.2021.001.0049 


\section{INTRODUÇÃO}

A estruturação de produtividade em larga escala no setor econômico, que visa alcançar diversas camadas de indivíduos, é um aspecto agregador de muitos entraves em questões socioambientais. Com isto, a atual proposta dessa produção tem ocasionado a diminuição de recursos naturais e exacerbada geração de resíduos (BICAS, 2016).

Nota-se que toda e quaisquer ordenação inadequada destes caroços de açaí, em vias públicas, gera problemas de cunho socioambiental como o entupimento dos dutos de drenagem, o que dificulta o escoamento e dispersão das águas pluviais. Como consequências, têm-se os alagamentos, ocasionando perda de domicílios e obstrução de ruas para mobilidade urbana, entre outros (BENTES, 2017); e possíveis vetores de doenças que se apropriam dos materiais jogados ao léu (JUNIO et al., 2013).

Neste contexto, tem-se a Política Nacional de Resíduos Sólidos (PNRS), instituída pela Lei no 12.305/2010, impulsiona e otimiza a elaboração de aparatos com intuito de reuso de resíduos sólidos gerados por diversas atividades, assim como propõe áreas devidas na disposição de materiais sem oportunidade de exploração (rejeitos) (BRASIL, 2010; ZELAYA, 2016).

O caroço de açaí pode ser moldado de diferentes formas, como na sua trituração tornando o material menos volumoso e simples de manejar na implantação ao substrato (FEIO et al., 2014), assim como pode se obter o biochar (biocarvão) por meio de processos químicos que influenciarão na sua composição. 0 biocarvão é um produto gerado a partir da calefação da biomassa, sem a inclusão de oxigênio na prospecção de elevadas temperaturas, caracterizado como um maciço abundante em carbono. Este procedimento é realizado pela Pirólise e tem a perspectiva de agregar o firmamento dos sólidos orgânicos (GRAY et al., 2014; LEHMANN et al., 2011).

Sabe-se que o biocarvão é um produto que se apresenta como um excelente material de otimização das condições do solo, tanto em seus atributos físicos (JUNIO et al., 2013; SOUSA, 2015) quanto químicos (BARROS, 2017), podendo ser aplicado no cultivo de espécies agrícolas e florestais e na recuperação de áreas degradadas.

Dentro deste cenário, objetivou-se avaliar o desenvolvimento de mudas de Paricá (Shizolobium amazonicum) em Latossolo Amarelo de textura média tratado com biocarvão à $350^{\circ} \mathrm{C}$ de caroço de açaí, através de análises morfológicas da parte aérea da planta e atributos químicos do solo. A Shizolobium amazonicum, fora escolhida pois possui características de ágil crescimento e utilidade em áreas degradadas. Com a utilização dos substratos propostos, visa-se a atenuação de custos com insumos, para uma espécie de rápido crescimento e de viabilidade econômica. Logo, espera-se obter bons resultados do biocarvão de caroço de açaí no desenvolvimento de mudas de Paricá (Shizolobium amazonicum) assim como o aproveitamento dos resíduos em substratos. 


\section{MATERIAIS E MÉTODOS}

\section{Caracterização do experimento}

Este estudo foi desenvolvido na Casa de Vegetação do Instituto de Ciências Agrárias - ICA pertencente à Universidade Federal Rural da Amazônia (UFRA), localizada na cidade de Belém/PA, nas coordenadas $01^{\circ} 27^{\prime} 18,29^{\prime \prime} \mathrm{S}$ e $48^{\circ} 26^{\prime} 19,01^{\prime \prime} \mathrm{O}$. O solo utilizado no ensaio foi o Latossolo Amarelo de textura média coletado no campus da UFRA, Belém, nas coordenadas $01^{\circ} 27^{\prime} 03,46^{\prime \prime} \mathrm{S}$ e $48^{\circ} 26^{\prime} 27,81^{\prime \prime} \mathrm{O}$.

Após coletado, o solo foi seco ao ar por 7 dias, destorroado e passado em peneira de malha $10 \mathrm{~mm}$ e alocado com as devidas proporções, em tubetes de $280 \mathrm{dm}^{3}$.

\section{Descrição dos tratamentos}

O experimento foi avaliado num período de 40 dias, com diferentes proporções de solo e biocarvão de caroço de açaí (BCA). Este seguiu a metodologia de Carvalho et al. (2017), com avaliações semanais de propriedades morfológicas da planta e, tendo como base o tempo e o tamanho apropriado para o plantio das mudas em campo, entre $20 \mathrm{~cm}$ a $35 \mathrm{~cm}$ de altura.

O experimento contou com dez tratamentos e quatro repetições, totalizando 40 tubetes instalados em casa de vegetação do Instituto de Ciências Agrárias - ICA, com delineamento inteiramente casualizado.

Os tratamentos são detalhados a seguir: T1 - 100\% de solo, sem adubação química, sem calagem e, sem adição de biocarvão; T2 - 100\% de solo, com adubação química conforme a necessidade da cultura e sem calagem e sem adição de biocarvão; T3 - 100\% solo com calagem, sem adubação e sem adição do biocarvão; T4 - 50\% de solo, 50\% de biocarvão de caroço de açaí, sem adubação química, e sem calagem; T5 - 50\% de solo, 50\% de biocarvão de caroço de açaí, com adubação química conforme a necessidade da cultura, e sem calagem; T6 - 50\% de solo, 50\% de biocarvão de caroço de açaí, sem adubação química conforme a necessidade da cultura, e com calagem; T7 - 25\% de solo, 75\% de biocarvão de caroço de açaí, sem adubação química e sem calagem; T8 - 25\% de solo, 75\% de biocarvão de caroço de açaí, com adubação química e sem calagem; T9 - 25\% de solo, 75\% de biocarvão de caroço de açaí, sem adubação química e com calagem; T10 - 100\% biocarvão de caroço de açaí.

Nos tratamentos (T3, T6, T9) que receberam calcário, a calagem foi realizada 20 dias antes da semeadura com intuito de elevar a saturação por bases do solo a 70\%. Neste período de incubação todos os tratamentos recebiam irrigação diariamente, em dose única (SATO, 2018). Passando-se uma semana após o transplantio, foi realizada adubação por cobertura de $\mathrm{N}, \mathrm{K}, \mathrm{S}, \mathrm{Mg}$, e Ca com adição de $2 \mathrm{~mL}$ de solução nutritiva nos tubetes selecionados previamente (T2, T5 e T8), contendo $1 \mathrm{~mL} / \mathrm{L}_{\text {de }} \mathrm{KH}_{2} \mathrm{SO}_{4} \mathrm{M}, 5 \mathrm{~mL} / \mathrm{L}$ de KNO${ }_{3}$ $\mathrm{M}, 5 \mathrm{~mL} / \mathrm{L}$ de $\mathrm{Ca}\left(\mathrm{NO}_{3}\right)_{2} \mathrm{M}, 2 \mathrm{~mL} / \mathrm{L}$ de $\mathrm{MgSO}_{4} \mathrm{M}$ e $1 \mathrm{~mL} / \mathrm{L}$ de Fe-EDTA.

\section{Obtenção das mudas de Paricá}

Utilizaram-se sementes da espécie Paricá (Shizolobium parahyba var. amazonicum (Huber ex Ducke) Barneby), devido ao seu rápido crescimento, bom desenvolvimento em temperaturas relativamente 
elevadas e por ser característica da Região Amazônica (SOUZA, 2015). Inicialmente, fez-se necessário uma seleção manual de 60 sementes, nas quais as mais bem padronizadas em relação a cor, tamanho e espessura, foram selecionadas.

As sementes foram selecionadas de acordo com essas características no intuito de evitar possíveis entraves e diferenciação de resultados (SHIMIZU et al., 2011). A seleção de sementes é essencial tendo em vista que a uniformidade por comprimento resulta num acréscimo de melhores condições no momento da semeadura (KRZYZANOWSKI et al., 1991; PÁDUA et al., 2010).

Foram efetuadas escarificações a fim de acelerar o processo de germinação das mudas quando fossem alocadas em substrato. A ação de escarificação ocorreu de modo manual por atrito com auxílio de uma lixa madeira, na intenção de acelerar a germinação. $O$ ato foi realizado na parte contrária ao eixo embrionário do elemento. Em razão das sementes deterem dormência tegumentar, tornou-se fundamental a utilização da escarificação para ruptura da mesma (FRIGOTTO et al., 2015).

Já escarificadas, receberam embebedamento por água destilada num período de $24 \mathrm{~h}$, com o intuito de mantê-las bem hidratadas para o semeio (SHIMIZU et al., 2011; NEVES et al., 2010). Passado este tempo, as sementes foram semeadas em um recipiente contendo vermiculita e casca de arroz na proporção 1:1 para que permitisse o desenvolvimento até uma estatura adequada para efetuar o transplante de local.

Cada muda foi introduzida em tubetes com capacidade de $280 \mathrm{dm}^{3}$, contendo solo e diferentes dosagens do biocarvão, açaí triturado e solo, totalizando 40 tubetes

\section{Obtenção do Biocarvão}

Quanto ao Biocarvão de Caroço de Açaí (BCA), este foi obtido a partir do processo de pirólise na temperatura de $350^{\circ} \mathrm{C}$, elaborado no Laboratório de Separações Térmicas da UFPA e teve suas análises efetuadas conforme os procedimentos metodológicos da Embrapa Amazônia Oriental (2011).

O biocarvão foi moído num aparelho específico cedido pelo Laboratório de Engenharia Química na UFPA (USIMAT - Usina de Materiais), o processo durou cerca de uma hora e a quantidade usada fora de 3 kg. A moagem do material disponível ocorreu em duas bateladas. Em virtude do instrumento não suportar uma grande quantidade de peso, as porções foram separadas em 1,5 kg. Cada parte sucedeu um período de trinta minutos.

\section{Análises morfológicas e massa seca das plantas}

Após 7 dias da semeadura, iniciaram-se as seguintes análises morfológicas: altura da parte aérea (APA), expressa em $\mathrm{cm}$ e diâmetro do coleto (DC), expresso em $\mathrm{mm}$. Repetindo as mesmas análises até o fim do experimento com intervalos de 7 dias. Ao término do experimento, as mudas de Paricá foram extraídas dos tubetes para realização das seguintes análises: massa seca da parte aérea (MSPA), expressa em g; massa seca do sistema radicular (MSR), expressa em g e; massa seca total (MST), expressa em g.

Para as medições da APA e DC, foram utilizados uma régua graduada e um paquímetro, com precisão de 0,01 mm. Após isso, com o auxílio de uma tesoura, as mudas foram separadas em parte aérea e sistema 
radicular. Já separadas as partes, e após limpeza do sistema radicular em água corrente foram submetidas à uma estufa de circulação forçada, a 70 C até atingirem peso constante. Com o uso de uma balança analítica, com precisão de três casas decimais, após o esfriamento das amostras, determinaram-se os pesos de MSPA e MSR. A MST foi obtida a partir da soma das massas secas da parte aérea e do sistema radicular, muda por muda. Determinados os resultados das análises supracitadas, os valores foram submetidos à equação abaixo, a fim de se obter o Índice de Qualidade de Dickson (IQD) (DICKSON et al., 1960).

$$
I Q D \frac{M S T_{(g)}}{\frac{H_{(\mathrm{cm})}}{D C_{(\mathrm{mm})}}+\frac{M S P A_{(g)}}{M S R_{(g)}}}(\text { eq.1) }
$$

\section{Análises estatísticas}

Os dados foram submetidos à análise de variância a $5 \%$ de probabilidade, sendo todas as médias atreladas pelo test T Student. Os valores foram incorporados no software ASSISTAT Versão 7.7 (Experimentos 1 e 2). Por fim, realizou-se a Correlação de Pearson apenas no experimento 2 com auxílio do Past 3.26.

\section{RESULTADOS E DISCUSSÃO}

Após a primeira semana de transplantio, todos os tratamentos que continham o biocarvão $(T 4, T 5$, T6, T7, T8, T9 e T10) não desenvolveram em relação aos de $100 \%$ solo $(T 1, T 2, T 3)$ pois as bases do coleto estavam todas queimadas. Deste modo, a realização as mensurações dos atributos de altura e diâmetro do coleto não se tornaram possíveis nos tratamentos citados.

A razão da mortandade dos tratamentos pode ser interligada com o índice hidrofóbico do biocarvão, onde a sua porosidade encontrada é influenciada pelo grau de temperatura utilizado na queima de pirólise, o que pode caracterizar uma ineficiência da capacidade de armazenamento de água pelo substrato (SUN et al., 2014). Isso é explicado pela atenuação na relação O:C, o que induz a retirada de conjuntos funcionais, sugerindo a perda de afinidade superficial do produto por água (SATO, 2018).

Mia et al. (2015) afirma que a taxa de aproveitamento do biocarvão, quando inserido em temperaturas elevadas, tem ápice menor, podendo atingir apenas $20 \%$ de produtividade no plantio. Tem-se quanto maior a exposição do material à queima, menos chances de fertilidade na cultura haverá. $\mathrm{O}$ que justifica o não desenvolvimento das mudas de paricá que possuem o composto como substrato. Em contrapartida, as mudas de Paricá nos tratamentos T1, T2 e T3, responderam de forma satisfatória no estudo, tornando-se possível as avalições seguintes.

Aferições em sua estrutura física ocorreram após sete dias de transplantio, avaliando sua altura e diâmetro do coleto. A tabela 1 corresponde as medições de altura calculadas durante o período de 35 dias do experimento.

Ao final do experimento, o tratamento T3 que corresponde a 100\% solo com calagem, sem adubação e sem adição do biocarvão, apresentou melhores resultados no teste t com média de $23,37 \mathrm{~cm}$. Enquanto o tratamento T1 teve menor média $(20,4 \mathrm{~cm})$. Sendo que, todos os tratamentos se diferenciaram no término 
de 35 dias (Tabela 1).

Para obtenção desses resultados, presume-se que alguns fatores foram essenciais para o desempenho das mudas. Segundo Tucci et al. (2010), características básicas como a contenção de teores de alumínio, a distribuição química de nutrientes essenciais, a potencialização no rendimento de outros elementos já dispostos no solo (N, P, K, S e MO) e a CTC mais ativa influenciam no desenvolvimento vegetal ao longo do tempo. $\mathrm{O}$ que possibilita melhor desenvolvimento radicular, presença do $\mathrm{Ca}$ e $\mathrm{Mg}$ em maior proporção, melhor condução das ações microbianas e dispersão de nutrientes provindos do material orgânico do composto (COSTA et al., 2008). Logo, estas e outras peculiaridades agregaram melhor crescimento do tratamento 3 em relação aos outros.

Tabela 1: Avaliação semanal da altura das mudas em cm.

\begin{tabular}{llll}
\hline TRAT. & T1 & T2 & T3 \\
\hline $\mathbf{7}$ dias & $14,7 \mathrm{bC}$ & $16,1 \mathrm{abD}$ & $16,9 \mathrm{aE}$ \\
$\mathbf{1 4}$ dias & $15,8 \mathrm{cC}$ & $17,15 \mathrm{bC}$ & $19,1 \mathrm{aD}$ \\
$\mathbf{2 1}$ dias & $17,32 \mathrm{cB}$ & $18,05 \mathrm{bB}$ & $19,9 \mathrm{aC}$ \\
$\mathbf{2 8}$ dias & $20 \mathrm{cA}$ & $21 \mathrm{bA}$ & $22,45 \mathrm{aB}$ \\
$\mathbf{3 5}$ dias & $20,4 \mathrm{cA}$ & $21,22 \mathrm{bA}$ & $23,37 \mathrm{aA}$ \\
\hline
\end{tabular}

*Médias seguidas de letras iguais maiúsculas na mesma coluna (para cada tratamento) não diferem entre si ao nível de $5 \%$ de significância pelo teste $t$ de Student. Médias seguidas de letras iguais minúsculas na mesma linha (para diferentes tratamentos) não diferem entre si ao nível de $5 \%$ de significância pelo teste t de Student. TRAT. = Tratamento.

Quanto ao diâmetro do coleto (Tabela 2), percebe-se que apenas na primeira semana de avaliação houve semelhança entre tratamentos. Assim sendo, presume-se que a partir do momento em que a adubação química e calagem reagiram nos tratamentos, houve variação significativa nos períodos posteriores.

Não houve diferença significativa nos tratamentos T1 e T3 nos períodos avaliados (Tabela 2). Notase a importância da calagem no melhor desenvolvimento e desempenho do substrato para promover qualidade de crescimento vegetal. Silva et al. (2008), afirmam que, em seu experimento com calagem em mudas de sumaúma (Ceiba pentandra L. Gaertn), obtiveram resultados mais eficientes comparados a outros sem acréscimo do calcário.

Portanto, avaliando os resultados da altura e diâmetro do coleto, notou-se que tanto T1 quanto T3, configuraram os menores e maiores valores de crescimento, respectivamente (Tabela 2). 0 primeiro (T1) não possuía nenhum tipo de método corretivo, tendo apenas 100\% de Latossolo Amarelo de textura média. Este solo tem características ácidas apontando saturação por bases baixa (V\% 25,31$)$. Atributo que possivelmente limitou melhor desenvolvimento da muda, uma vez que a acidez afeta na quantidade disponível de nutrientes do solo de modo direto ou indireto (FAVARE et al., 2012).

Por outro lado, o tratamento (T3) além de conter 100\% Latossolo, continha dosagem de calcário a fim de corrigir a sua acidez. O método da calagem tem como função o abastecimento de Ca e Mg. A carência destes elementos atenua o crescimento das raízes, que por sua vez dificulta a obtenção de outros nutrientes no solo; este fator tona-se mais restringente que a toxidade do Al (COSTA et al., 2008). Assim sendo, a calagem explica melhores resultados no T3 comparados ao T1 e T2. 
Tabela 2: Avaliação semanal do diâmetro do coleto das mudas em mm.

\begin{tabular}{llll}
\hline TRAT. & T1 & T2 & T3 \\
\hline $\mathbf{7}$ dias & $3,25 \mathrm{aA}$ & $3,36 \mathrm{aB}$ & $3,71 \mathrm{aA}$ \\
$\mathbf{1 4}$ dias & $3,33 \mathrm{bA}$ & $3,53 \mathrm{abAB}$ & $3,78 \mathrm{aA}$ \\
$\mathbf{2 1}$ dias & $3,35 \mathrm{bA}$ & $3,56 \mathrm{aAB}$ & $3,81 \mathrm{aA}$ \\
$\mathbf{2 8}$ dias & $3,46 \mathrm{bA}$ & $3,58 \mathrm{bAB}$ & $3,82 \mathrm{aA}$ \\
$\mathbf{3 5}$ dias & $3,47 \mathrm{bA}$ & $3,82 \mathrm{abA}$ & $3,89 \mathrm{aA}$ \\
\hline
\end{tabular}

*Médias seguidas de letras iguais maiúsculas na mesma coluna (para cada tratamento) não diferem entre si ao nível de $5 \%$ de significância pelo teste $t$ de Student.

Médias seguidas de letras iguais minúsculas na mesma linha (para diferentes tratamentos) não diferem entre si ao nível de $5 \%$ de significância pelo teste $t$ de Student. TRAT. = Tratamento

É notado que o T3 teve maior produção de matéria da parte aérea das folhas (Tabela 3), podendo ser atribuído à calagem efetuada neste tratamento. Para Souza (2015), ao realizar pesquisas referentes ao Paricá quanto a nutrição da espécie em conjunto ao calcário; o tratamento alcançou efeitos relevantes na constatação de que o Ca tem grande valia no manejo eficiente do solo, em virtude da substância acrescentar maior produtividade da massa seca, crescimento radicular e expansão da parte aérea. Já o T2 se assemelhou tanto com T1 quanto T3, tendo como justificativa a implantação da adubação química após algumas semanas do plantio (SATO, 2018).

Então, torna-se importante a quantidade de matéria seca produzida pela folha pois, quanto maior a sua massa seca, mais elevado será a obtenção de nutrientes pela fotossíntese, agregando crescimento significativo às mudas e melhoramento na estrutura interna com o cloroplasto bem ativo nos processos (MARANHO et al., 2012).

Quanto à raiz, não houve diferenciação significativa entre os tratamentos (Tabela 3). Resultados semelhantes foram encontrados no experimento de Marques et al. (2004) que ao analisarem a quantidade de massa seca presente na mesma espécie caracterizada, não constataram variação relevante ao término do experimento.

Portanto, a avaliação da massa seca da raiz é de suma importância em projetar a demanda de vida que a muda terá, além de conduzir seu desenvolvimento primário. Então, sabe-se que quanto maior a parte radicular, a planta ganhará quantidade elevada e essencial de nutrientes para sobrevivência por meio da absorção de água e demais sais fundamentais no ciclo de vida (TAIZ et al., 2009).

A matéria seca total é descrita como a soma das médias da MSPA e MSR (FRIGOTTO et al., 2015). Após todas as verificações, constatou-se que o T3 permaneceu com a maior média, indicando que o processo de calagem pode ser eficaz no cultivo de mudas (Tabela 3 ).

Tabela 3: Matéria seca da parte aérea, raiz e total das mudas (T1, T2 e T3).

* Médias seguidas de letras iguais minúsculas na mesma linha não diferem entre si ao nível de $5 \%$ de significância pelo teste $t$ de Student.

\begin{tabular}{llll}
\hline & T1 & T2 & T3 \\
\hline MSPA (g.planta-1) & $1,57 \mathrm{~b}$ & $1,60 \mathrm{ab}$ & $1,68 \mathrm{a}$ \\
MSR (g.planta-1) & $0,52 \mathrm{a}$ & $0,61 \mathrm{a}$ & $0,67 \mathrm{a}$ \\
MST (g.planta-1) & 2,09 & 2,22 & 2,36 \\
\hline
\end{tabular}

Para Hunt (1990), é preferível que o valor mínimo de IQD seja de 0,20 afirmando ser um excelente alvo na qualidade das mudas. Ao verificar a tabela 4 , tendo como base o número disposto por Hunt, todas os tratamentos mostraram-se aptos a serem cultivados com os valores alternando de 0,23 a 0,27. 
Logo, mesmo que o T3 tenha se destacado por suas particularidades morfológicas ao longo das análises de MSPA, MSR, altura e diâmetro do coleto, o T2 mostrou-se também eficiente na implantação deste tratamento em áreas degradadas com auxílio do Paricá, pois ao decorrer do período seu IQD obteve variação com média que está em acordo com o proposto por Hunt (1990), sendo possível melhor aproveitamento deste tratamento na utilização destes espaços que demandam bastante tempo para se recuperar.

Porém, vale ressaltar que são necessários mais estudos para considerar esse valor em relação a cada espécie em diferentes condições de cultivo, pois Hunt (1990) apenas utilizou parâmetros após o transplantio das mudas, não considerando o tipo de substrato e quais os tratamentos são submetidos, o tempo para germinação de espécies diferentes, entre outros fatores (SATO, 2018). Contudo, o Índice de Qualidade de Dickson, tem-se este como um dos melhores métodos de averiguar a qualidade das mudas estudadas, em razão de que ele possui a proposta de mensurar diversos fatores de morfologia fundamentais numa determinada fórmula (LUCENA et al., 2011).

Utiliza-se este índice a fim de evitar suposições errôneas nas escolhas de mudas e tratamentos, por isso avaliam-se os parâmetros unidos diminuindo o risco de selecionar mudas menos eficientes. Estes fatos não aconteceriam se usassem os indicadores morfológicos de modo singular, pois a margem de erro seria maior. Nem todas as mudas que possuem altura, diâmetro e entre outros atributos altos, são necessariamente projetados a serem os melhores no quesito de sobrevivência futura, assim como fora observado nos dados anteriores da Tabela 2 e Tabela 3. Este é o motivo de não ser eficaz a seleção de um único parâmetro, mas sim vários (LOPES, 2005).

Tabela 4: Avaliação Semanal do Índice de Qualidade de Dickson.

\begin{tabular}{ll}
\hline Avaliação & \\
\hline T1 & 0,23 \\
T2 & 0,27 \\
T3 & 0,27 \\
\hline
\end{tabular}

\section{CONCLUSÕES}

Conclui-se que o tratamento T3 (100\% solo com calagem, sem adubação) proporcionou melhor desenvolvimento das mudas de Paricá, com maior crescimento da mesma em altura $(23,37 \mathrm{~cm})$, diâmetro do coleto $(3,89 \mathrm{~mm}), \operatorname{MSPA}(1,68 \mathrm{~g}), \operatorname{MSR}(0,67 \mathrm{~g}), \operatorname{MST}(2,36 \mathrm{~g})$, assim como um índice de qualidade de Dickson $(0,27)$ considerado adequado. Em contrapartida, neste último parâmetro (IQD), o tratamento T2 obteve resultado igual a T3 de 0,27 ao final dos 35 dias de experimento, concedendo ao T2 (100\% solo com adubação química) chances e possibilidades de mais estudos para aplicação do mesmo em outros experimentos.

\section{REFERÊNCIAS}

BARROS, D. L.. Caracterização e utilização de biocarvão proveniente de resíduo madeireiro na produção de mudas florestal, frutífera e a campo de teca (Tectona grandis L.f.). Tese (Doutorado em Agronomia) - Universidade Federal de Lavras, Lavras, 2017.

BENTES, E. S.; HOMMA, A. K. O.; SANTOS, C. A. N..

Exportações de polpa de açaí do estado do Pará: situação atual e perspectivas. In: CONGRESSO DA SOCIEDADE BRASILEIRA DE ECONOMIA, ADMINISTRAÇÃO E SOCIOLOGIA RURAL, 55; INOVAÇÃO, EXTENSÃO E COOPERAÇÃO PARA O DESENVOLVIMENTO. Anais. Brasília: SOBER, 2017.

BICAS, T. C.. Valorização de subprodutos agroindustriais: potencial utilização em indústrias alimentícias e de biotecnologia. Monografia (Bacharelado) - Universidade 
Tecnológica Federal do Paraná, Pato Branco, 2016.

BRASIL. Lei n. 12.305 de $\mathbf{2}$ de agosto de 2010. Institui a Política Nacional de Resíduos Sólidos; altera a Lei no 9.605, de 12 de fevereiro de 1998; e dá outras providências. Brasília: DOU, 2010.

CARVALHO, M. C. S.; NASCENTE, A. S.; BARBOSA, G. F.; MUTADIUA, C. A. P.; DENARDIN, J. E.. Época de semeadura afetando o desenvolvimento de cultivares de feijão em Lichinga, província de Niassa, Moçambique. Rev. Ceres, v.64 n.5, p.532-539, 2017. DOI: http://dx.doi.org/10.1590/0034737x201764050011

COSTA, L. C. B.; PINTO, J. E. B. P.; CASTRO, E. M.; VILELA, S. K. B.; M; CORRÊA, R. M.; REIS, É. S.; ALVES, P. B.; NICULAU, E. S.. Tipos e doses de adubação orgânica no crescimento, no rendimento e na composição química do óleo essencial de elixir paregórico. Ciência Rural, Santa Maria, v.38, n.8, p.2173-2180, 2008

DICKSON, A.; LEAF, A. L.; HOSNER, J. F.. Quality appraisal of white spruce and white pine seedling stock in nurseries. Forest Chronicle, v.36, p.10-13, 1960. DOI: https://doi.org/10.5558/tfc36010-1

FAVARE, L. G. D.; GUERRINI, I. A.; BACKES, C.. Níveis crescentes de saturação por bases e desenvolvimento inicial de teca em um Latossolo de textura média. Ciência Florestal, v.22, n.4, p.693-702, 2012. DOI: http://dx.doi.org/10.5902/198050987551

FEIO, V. F.; GIRARD, L.; MENDONÇA, N.. Problemática da geração de efluentes oriundos do processamento de açaí na região metropolitana de Belém-PA. Revista Monografias Ambientais v.13, n.3, p.3335-3340, 2014. DOI: https://doi.org/10.5902/2236130813370

FRIGOTTO, T.; BRUN, E. J.; MEZZALIRA, C. C.; NAVROSKI, M. C.; BIZ, S.; RIBEIRO, R. R.. Desenvolvimento de mudas de Schizolobium amazonicum Huber ex Ducke em diferentes ambientes em viveiro. ENFLO Ecologia e Nutrição Florestal, v.3, n.1, 2015

GRAY, M.; JOHNSON, M. G.; DRAGILA, M. I.; KLEBER, M.. Water uptake in biochars: the roles of porosity and hydrophobicity. Biomass and Bioenergy, Oxford, v.61, p.196-205, 2014. DOI:

\section{https://doi.org/10.1016/j.biombioe.2013.12.010}

HUNT, G. A.. Effect of styroblock design and cooper treatment on morphology of conifer seedlings. In: ROSE, R.; CAMPBELL, S. J.; LANDIS, T. D.. Target seedling symposium, meeting of the western forest nursery associations, general technichal report RM-200. Roseburg: Proceedings Collins: United States Departament of Agriculture, Forest Service, 1990. p.218-222.

JUNIO, G. R. Z.; SAMPAIO, R. A.; NASCIMENTO, A. L.; SANTOS, G. B.; SANTOS, L. D. T.; LUIZ, A.; FERNANDES, L. A. Produtividade de milho adubado com composto de lodo de esgoto e fosfato natural de Gafsa. Revista Brasileira de Engenharia Agrícola e Ambiental-Agriambi, v.17, n.7, 2013. DOI:

https://doi.org/10.1590/S1415-43662013000700003

KRZYZANOWSKI, F. C.; FRANÇA-NETO, J. B.; HENNING, A. A..
Relato dos testes de vigor disponíveis para as grandes culturas. Embrapa Soja-Artigo em periódico indexado, 1991

LOPES, E. D.. Qualidade de mudas de Eucalyptus urophylla, E. camaldulensis e E. citriodora produzidas em blocos prensados e em dois modelos de tubetes e seu 26 desempenho no campo. Dissertação (Mestrado em Agronomia) - Universidade Estadual do Sudoeste da Bahia, Vitória da Conquista, 2005

LEHMANN, J.; RILLING, M.; THIES, J.; MASIELLO, C. A.; HOCKADAY, W. C.; CROWLEY, D.. Biochar effects on soil biota: a review. Soil and Biochemistry, Elmsford, v.43, p.1812-1836, 2011. DOI:

https://doi.org/10.1016/j.soilbio.2011.04.022

LUCENA, R. R. M.; BATISTA, T. M. V.; DOMBROSKI, J. L. D.; LOPES, W. A. R.; RODRIGUES, G. S. O.. Medição de área foliar de aceroleira. Revista Caatinga, Mossoró, v.24, p.40-45, 2011.

MARANHO, Á. S.; PAIVA, A. V.. Produção de mudas de Physocalymma scaberrimum em substratos compostos por diferentes porcentagens de resíduo orgânico de açaí. Floresta, v.42, n.2, p.399-408, 2012. DOI: http://dx.doi.org/10.5380/rf.v42i2.19220

MARQUES, T. C.; CARVALHO, J. G.; LACERDA, M. P. C.; MOTA, P. E. F.. Crescimento inicial do paricá (Schizolobium Amazonicum) sob omissão de nutrientes e de sódio em solução nutritiva. Cerne, Lavras, v.10, n.2, p.184-195, 2004.

MIA, S.; UDDIN, N.; HOSSAIN, S. A. A. M.; AMIN, R.; METE, F. Z.; HIEMSTRA, T.. Production of biochar for soil application: A comparative study of three kiln models. Pedosphere, v.25, n.5, p.696-702, 2015. DOI: https://doi.org/10.1016/S10020160(15)30050-3

NEVES, G.; DALCHIAVON, F. C.; CARGNIN-STIELER, M.. Superação da dormência em sementes de Schizolobium amazonicum. UNICiências, v.14, n.2, 2010. DOI: https://doi.org/10.17921/1415-5141.2010v14n2p\%25p

SATO, M. K.. Biocarvão de resíduos de açaí como condicionante de solos. Tese (Doutorado em Agronomia) Universidade Federal Rural da Amazônia, Belém, 2018.

SHIMIZU, E. S. C.; PINHEIRO, H. A.; COSTA, M. A.; SANTOS FILHO, B. G.. Aspectos fisiológicos da germinação e da qualidade de plântulas de Schizolobium amazonicum em resposta à escarificação das sementes em lixa e água quente. Revista Árvore, v.35, n.4, p.791-800, 2011. DOI: http://dx.doi.org/10.1590/S0100-67622011000500004

SILVA, A. R. M.; TUCCI, C. A. F.; LIMA, H. N.; SOUZA, P. A.; VENTURIN, N.. Efeitos de doses crescentes de calcário na produção de mudas de sumaúma (Ceiba pentandra L. Gaertn). Floresta, Curitiba, v.38, n.2, 2008. DOI: http://dx.doi.org/10.5380/rf.v38i2.11623

SOUSA, A. A. T. C.. Biochar de lodo de esgoto: efeitos no solo e na planta no cultivo de rabanete. Dissertação (Mestrado em Agronomia) - Universidade de Brasília, Brasília, 2015.

SUN, Y.; GAO, B.; YAO, Y.; FANG, J.; ZHANG, M.; ZHOU, Y.; CHEN, H.; YANG, L.. Effects of feedstock type, production 
method, and pyrolysis temperature on biochar and hydrochar properties. Chemical Engineering Journal, v.240, p.574-578, 2014. DOI:

https://doi.org/10.1016/j.cej.2013.10.081

PÁDUA, T. R. P.; SILVA, C. A.; DIA, B. O.. Nutrição e crescimento do algodoeiro em Latossolo sob 1481 diferentes coberturas vegetais e manejo de calagem. Ciênc. Agrotec., Lavras, v.32, n.5, p.1481-1490, 2008. DOI: http://dx.doi.org/10.1590/S1413-70542008000500019

TAIZ, L.; ZEIGER, E.. Fisiologia vegetal. 4 ed. Porto Alegre: Artmed, 2009.
TUCCI, C. A. F.; LIMA, H. N.; GAMA, A. S.; COSTA, H. S.; SOUZA, P. A.. Efeitos de doses crescentes de calcário em solo Latossolo Amarelo na produção de mudas de pau-de-balsa (Ochroma lagopus sw.; bombacaceae). Acta Amaz., Manaus, v.40, n.3, 2010. DOI:

http://dx.doi.org/10.1590/S0044-59672010000300013

ZELAYA, K. P. S.. Caracterização de biocarvão de lodo de esgoto e bagaço de cana-de-açúcar e efeitos no cultivo de beterraba. Dissertação (Mestrado em Produção Vegetal) Universidade Federal de Minas Gerais, Montes Claros, 2016.

A CBPC - Companhia Brasileira de Produção Científica (CNPJ: 11.221.422/0001-03) detém os direitos materiais desta publicação. Os direitos referem-se à publicação do trabalho em qualquer parte do mundo, incluindo os direitos às renovações, expansões e disseminações da contribuição, bem como outros direitos subsidiários. Todos os trabalhos publicados eletronicamente poderão posteriormente ser publicados em coletâneas impressas sob coordenação da Sustenere Publishing, da Companhia Brasileira de Produção Científica e seus parceiros autorizados. Os (as) autores (as) preservam os direitos autorais, mas não têm permissão para a publicação da contribuição em outro meio, impresso ou digital, em português ou em tradução. 